Ekuitas: Jurnal Pendidikan Ekonomi

Volume 9, Number 1, Tahun 2021, pp. 109-115

P-ISSN : 2354-6107E-ISSN : 2549-2292

DOI : 10.23887 /ekuitas.v9i1.28034

Open Access: https://ejournal.undiksha.ac.id/index.php/EKU

\title{
Meningkatkan Aktivitas Belajar Mata Pelajaran Ekonomi Melalui Model Pembelajaran Kooperatif Tipe TPS dan TIPE Jigsaw
}

\author{
Putu Kusuma Adnyani ${ }^{1 *}$, Lulup Endah Tripalupi ${ }^{2}$ \\ 1,2Universitas Pendidikan Ganesha, Singaraja - Indonesia
}

\author{
ARTICLE INFO \\ Article history: \\ Received August, 112020 \\ Received in revised form \\ June, 42021 \\ Accepted June, 42021 \\ Available online June, 28 \\ 2020 \\ Kata Kunci: \\ Aktivitas belajar, model \\ pembelajaran. \\ Keywords: \\ Learning activity, learning \\ model.
}

\begin{abstract}
ABSTRAK
Dalam proses pembelajaran guru berperan dalam pemilihan model pembelajaran. Pemilihan model pembelajaran yang tepat akan berdampak pada aktivitas belajar siswa. Oleh karena itu, melalui penelitian ini bertujuan untuk mengetahui perbedaan (1) aktivitas belajar ekonomi siswa kelompok eksperimen, (2) aktivitas belajar ekonomi siswa kelompok kontrol, dan (3) perbedaan aktivitas belajar siswa antara kelompok eksperimen dan kelompok kontrol. Penelitian ini menggunakan rancangan eksperimental. Data dikumpulkan dengan menggunakan observasi dan dokumentasi. Data analisis dengan Independent Sample t-test. Hasil penelitian menunjukkan bahwa (1) aktivitas belajar ekonomi siswa kelompok eksperimen berada dalam kategori sangat aktif, (2) aktivitas belajar ekonomi siswa kelompok kontrol dalam kategori aktif, dan (3) terdapat perbedaan yang siginifikan aktivitas belajar siswa antara kelompok eksperimen dan kelompok kontrol.
\end{abstract}

\section{ABSTRACT}

In the classroom activity the teacher plays a role in the selection of learning models. It will have a great impact on student learning activities. Thus, this research aimed to find out the differences (1) students classroom activity of the experiment group, (2) students classroom activity of the control group, and (3) the significant differences of student classroom activities between the experimental group and the control group. Moreover, the research of study was experimental research. The instruments were using an observation form and documentation and the data were analysing by Independent Sample t-test. The results of this study disclosed (1) the experimental group showed very dynamic, (2) the control group were dynamic and (3) there were significant differences in the learning activities between the experimental group and control group students.

* Corresponding author.

E-mail : Kusumaadnyani13@gmail.com (Putu Kusuma Adnyani) 


\section{Pendahuluan}

Pendidikan ialah usaha sadar terencana untuk dapat mewujudkan suasana belajar secara aktif untuk mengembangkan potensi yang dimiliki (Suriati, 2019). Pendidikan adalah suatu pembelajaran yang berlaku sepanjang hayat serta sangat berperan penting dalam kehidupan manusia (Ayuwanti, 2017). Pendidikan dan manusia tidak dapat dipisahkan, karena pendidikan sangat penting untuk menunjang kehidupan manusia (Canessia D.Putri et al., 2019). Manusia dibekali akal dan pikiran untuk menjalani kehidupannya, dengan pikiran serta akal yang dimiliki manusia dapat berkembang untuk menambah wawasan dan pengetahuannya. Dalam konteksnya pendidikan yang ditempuh ada pendidikan formal dan non formal. Pendidikan formal merupakan pendidikan yang berlangsung disekolah sedangkan pendidikan non formal adalah pendidikan yang belangsung dalam keluarga ataupun masyarakat sekitar. Maka pendidikan sangat diperlukan bagi semua orang untuk memperoleh manusia yang berkualitas. Upaya meningkatkan kualitas pendidikan memerlukan peningkatan pada kualitas pembelajaran.

Salah satu upaya yang dimaksud adalah pengembangan kurikulum. Kurikulum adalah salah satu unsur sumber daya pendidikan yang memberikan peran yang signifikan dalam mewujudkan proses berkembangnya kualitas potensi siswa (Sari et al., 2017). Kurikulum dirancang untuk memperlancar proses kegiatan pembelajaran dengan tujuan memperbaiki mutu dan kualitas pendidikan di Indonesia. Kurikulum yang di gunakan Indonesia saat ini ialah kurikulum 2013 (Canessia D.Putri et al., 2019). Dalam kurikulum 2013 berisi tentang penyempurnaan pola pikir. Pola pikir yang dimaksud dalam Peraturan Menteri Pendidikan dan Kebudayaan (Permendikbud, 2014) yaitu pembelajaran yang berpusat pada guru berubah menjadi berpusat pada peserta didik.

Dalam proses pembelajaran peserta didik berupaya mengelaborasikan kemampuannya dengan berperan sangat aktif saat proses pembelajaran berlangsung. Menurut (Dr. Rusman, 2012) pembelajaran merupakan proses interaksi peserta didik dengan guru dan sumber belajar pada suatu lingkungan belajar. Proses pembelajaran perlu direncanakan, dilaksanakan, dinilai, serta diawasi agar terlaksana secara efektif, efisien dan kondusif. Menurut Slameto (2010) belajar merupakan suatu proses perubahan tingkah laku sebagai hasil dari interaksi dengan lingkungannya dalam memenuhi kebutuhan hidupnya. Konsep pembelajaran saat ini telah berubah dari guru mengajar menjadi siswa yang belajar. Dalam konsep tersebut, siswa tidak lagi diposisikan sebagai obyek belajar, melainkan diposisikan sebagai subyek belajar yang dilihat sesuai minat, bakat, serta kemampuan yang dimilikinya. Pembelajaran seperti ini disebut pembelajaran yang berpusat pada siswa (student center). Dengan pembelajaran yang berpusat pada siswa tersebut akan membuat siswa menjadi lebih aktif dalam menyelesaikan soal atau mengembangkan kemampuannya agar mereka lebih kreatif dan bertanggung jawab.

Di sekolah aktivitas belajar sangat diperlukan untuk mencapai suatu tujuan yang diarahkan untuk mengembangkan aktivitas siswa agar terjadi suatu interaksi yang baik dalam pembelajaran (Sardiman, 2011). Dalam pembelajaran banyak hal yang bisa dilakukan untuk meningkatkan aktivitas belajar, seperti menerapkan berbagai metode, strategi atau model pembelajaran yang bisa memvariasikan cara mengajar didalam kelas. Menggunakan model pembelajaran memberikan inovasi baru dalam pelaksanaan pembelajaran dikelas, sehingga memberikan suasana baru untuk siswa dalam mengembangkan aktivitasnya didalam kelas.

Salah satu model pembelajaran yang dapat meningkatkan aktivitas belajar siswa adalah model pembelajaran kooperatif tipe Think Pair Share (TPS) dan model pembelajaran kooperatif tipe jigsaw. Model pembelajaran kooperatif tipe TPS merupakan salah satu model pembelajaran yang sangat menarik, karena model pembelajaran ini dikembangkan dari teori kontruktivisme yang merupakan perpaduan antara belajar secara mandiri dan secara berkelompok (Karyawati, N. K., Murda, I. N. \& W, 2014). Model pembelajaran kooperatif tipe TPS merupakan salah satu model pembelajaan kooperatif sederhana yang memberi kesempatan pada siswa untuk bekerja sendiri serta bekerja sama dengan orang lain (Ibrahim, 2011). Model pembelajaran TPS ini siswa dipergunakan untuk melatih siswa untuk berani mengemukakan pendapat secara tepat serta mendorong siswa untuk meningkatkan kerjasama antar siswa lain. Model TPS ini memberikan kesempatan pada siswa untuk dapat mendiskusikan ide-ide mereka dan dapat melatih mereka untuk menyelesaikan masalah (Januartini et al., 2016).

Dalam model pembelajaran TPS terdiri dari tiga langkah yaitu . Pertama berpikir (thinking), guru memberikan pertanyaan yang terkait dengan mata pelajaran dan meminta siswa untuk memikirkan jawaban sendiri dan aktif mencari referensi agar lebih mudah memecahkan masalah atau soal yang guru berikan. Kedua berpasangan (pair), guru meminta siswa untuk berpasangan mendiskusikan jawaban yang diperoleh. Diskusi merupakan langkah untuk siswa menyatukan pendapat masing-masing. Hal ini mendorong siswa untuk lebih aktif menyampaikan pendapat dan menerima masukan orang lain, dan mampu bekerjasama dengan orang lain. Ketiga berbagi (share), setelah mendiskusikan pertanyaan yang diberikan, siswa diminta 
untuk membagikan hasil yang telah mereka diskusikan dengan pasangan masing-masing kepada seluruh kelas. Model TPS merupakan salah satu model pembelajaran yang sangat menarik dan menantang, karena terdapat pendalaman materi yang membuat siswa mampu menguasai dan mendalami sebuah materi yang dibahas dengan lebih baik (Darmadi, 2014).

Model pembelajaran kooperatif tipe jigsaw ialah model pembelajaran kooperatif yang menitikberatkan siswa dengan kerja kelompok dalam bentuk kelompok kecil (Dr. Rusman, 2012). Dalam model pembelajaran kooperatif ini siswa memiliki lebih banyak kesempatan yang dapat dilakukan untuk lebih aktif meningkatkan keterampilan komunikasi, saling bertanggung jawab terhadap keberhasilan kelompok, ketuntasan materi yang dipelajari dan menyampaikan informasi kepada kelompok lain. Dengan model pembelajaran jigsaw siswa tidak hanya sebagai pendengar, namun akan terlibat aktif pada saat proses pembelajaran berlangsung (Redno setiawan, 2018).

Dalam model pembelajaran kooperatif tipe jigsaw terdiri dari enam langkah yaitu . Fase pertama, guru menyampaikan tujuan dan mempersiapkan siswa untuk belajasr. Fase kedua, guru membentuk kelompok besar yang heterogen yang berjumlah 4-5 orang yang disebut kelompok asal. Fase ketiga, guru membagikan tugas dalam setiap kelompok. Materi yang diberikan dalam masing-masing kelompok berbeda. Fase keempat, siswa berdiskusi dalam kelompok (kelompok ahli) berdasarkan masing-masing materi yang diberikan. Fase kelima, siswa berdiskusi kembali dalam kelompok asalnya masing-masing dengan ketentuan guru. Fase keenam, guru meminta masing-masing kelompok untuk mempresentasikan hasil diskusi tersebut terhadap seluruh kelas dan guru memberikan penilaian terkait topik yang dipresentasikan (Suprijono, 2013).

Model pembelajaran kooperatif tipe TPS berfungsi untuk meningkatkan aktivitas belajar, karena dalam model pembelajaran ini siswa dikehendaki untuk bekerja secara mandiri, aktif dalam mencari referensi dan bekerjasama saling membantu siswa lain dalam kelompok kecil (Kusuma \& Aisyah, 2012). Selain model pembelajaran kooperatif tipe TPS, tipe jigsaw mempunyai fungsi untuk meningkatkan aktivitas belajar siswa dan saling membantu menguasai materi pembelajaran (Isjoni, 2013). Menurut (Apriliawati, 2011) aktivitas belajar merupakan suatu kegiatan yang siswa dapat lakukan dalam proses pembelajaran. Aktivitas siswa selama proses pembelajaran mencerminkan adanya keinginan siswa untuk belajar.

Aktivitas belajar merupakan hal yang sangat penting dalam proses pembelajaran (Catur Saputro et al., 2015). Menurut (Oemar Hamalik, 2010) aktivitas belajar dapat didefinisikan sebagai aktivitas yang diberikan oleh pembelajar dalam situasi belajar mengajar. Berbagai aktivitas yang diarahkan untuk meningkatkan aktivitas belajar dengan proses interaksi yang baik dalam pembelajaran. Menurut (Sardiman, 2011) dibagi menjadi delapan jenis yaitu . Visual activities yaitu, membaca, memperhatikan, dan pecobaan pekerjaan orang lain. Oral activities yaitu, menyatakan, merumuskan, memberi saran dan mengadakan wawancara. Listening activities yaitu, mendengarkan percakapan, diskusi, dan musik. Writing activities yaitu, menulis cerita, karangan, laporan, angket, menyalin. Drawing activities yaitu, menggambarkan, membuat grafik, peta, dan diagram. Motor activities yaitu, melakukan percobaan, membuat konstruksi, bermain, berkebun dan bertenak. Mental activities yaitu, menanggapi, mengingat, memecahkan soal, menganalisis, dan mengambil keputusan. Emotional activities yaitu, menaruh minat, merasa bosan, gembira, bersemangat, bergembira, bergairah, dan tenang.

Berdasarkan hasil observasi yang peneliti lakukan, masalah yang terjadi di kelas X IPS 1 dan kelas X IPS 2 di SMA Negeri 1 Negara ialah aktivitas belajar yang belum optimal pada mata pelajaran ekonomi. Hal ini terlihat dari perolehan data awal pada kelas X IPS 1 perolehan nilai rata-rata yang dibawah KKM berjumlah 69,29\% dari 35 orang peserta didik. Sedangkan pada kelas X IPS 2 perolehan nilai rata-rata yang dibawah KKM berjumlah 68,89\% dari 35 orang peserta didik. Daya serap pada kelas X IPS 1 dan kelas X IPS 2 berjumlah 69\% dengan Kriteria Ketuntasan Minimum (KKM) untuk mata pelajaran ekonomi adalah 70.

Hasil koordinasi peneliti dengan guru pengampu mata pelajaran ekonomi diketahui bahwa penyebab menurunnya aktivitas belajar pada kelas X IPS 1 dan kelas X IPS 2 dikarenakan minimnya keaktifan siswa saat menyimak pembelajaran, kurangnya percaya diri dalam mengemukakan pendapat, dan jam pelajaran yang berbeda. Pada kelas X IPS 1 jam pelajaran untuk ekonomi ada pada jam 8-10 (13.00 - 15.00) sedangkan untuk kelas X IPS 2 ada pada jam 3-5 (08.30 - 11.05). Hal tersebut menunjukkan aktivitas belajar pada kelas X IPS 1 dan kelas X IPS 2 belum tercapai secara optimal.

Berdasarkan yang telah di paparkan, peneliti dapat mengkaji apakah penerapan model pembelajaran kooperatif tipe TPS pada kelas X IPS 1 dan model pembelajaran kooperatif tipe jigsaw pada kelas X IPS 2 dapat meningkatkan aktivitas belajar dengan mata pelajaran yang sama namun dengan perlakukan model yang berbeda dan aktivitias belajar pada kelas X IPS 1 dan kelas X IPS 2 di SMA Negeri 1 Negara akan dibandingkan. 


\section{Metode}

Rancangan penelitian yang digunakan dalam penelitian ini ialah eksperimen dengan pendekatan komparatif. Penelitian komparatif yaitu suatu penelitian yang bersifat membandingkan satu variabel atau lebih pada dua sampel yang berbeda atau pada waktu yang berbeda. Metode ini dipilih sesuai penelitian yang ingin dicapai yaitu meningkatkan aktivitas belajar dengan perlakukan yang berbeda. Metode eksperimen yang digunakan ialah metode eksperimen semu (quasi eksperimen) dalam bentuk Non Equivalent Posttest Only Control Grup Design.

Tabel 1. Desain Penelitian

\begin{tabular}{lll}
\hline Kelompok & Perlakuan & Posttest \\
\hline KE & $\mathrm{X}_{1}$ & $\mathrm{O}_{1}$ \\
KK & $\mathrm{X}_{2}$ & $\mathrm{O}_{2}$ \\
\hline
\end{tabular}

Lokasi penelitian ini adalah di SMA Negeri 1 Negara. Subyek penelitian ini adalah siswa kelas X IPS 1 dan kelas X IPS 2. Sedangkan Obyek penelitian ini adalah penerapan model pembelajaran kooperatif tipe TPS dan tipe Jigsaw untuk meningkatkan aktivitas belajar. Jenis data yang digunakan dalam penelitian ini ialah kualitatif. Data kualitatif ini dapat menghasilkan data aktivitas belajar dengan setelah diterapkan model pembelajaran kooperatif tipe TPS dan tipe jigsaw. Sumber data yang digunakan ialah data primer. Data primer ini diperoleh secara langsung dari aktivitas belajar kelas X IPS 1 dan X IPS 2 pada penerapan model pembelajaran kooperatif tipe TPS dan tipe jigsaw.

Metode pengumpulan data yang digunakan dalam penelitian ini ialah metode observasi dan dokumentasi dengan menggunakan instrumen lembar observasi aktivitas belajar. Setelah data terkumpul, teknik analisis yang digunakan ialah uji beda ( $t_{\text {test}}$ ) dengan dua sampel bebas (Independent sample $t$-test).

\section{Hasil dan Pembahasan Hasil Penelitian}

Berdasarkan hasil penelitian yang telah dilakukan dengan mengamati aktivitas belajar ekonomi siswa kelompok eksperimen dan kelompok kontrol diperoleh skor secara total dan indikator seperti pada tabel 2 dan pada tabel 3.

Tabel 2. Aktivitas belajar Ekonomi siswa Kelompok Eksperimen

\begin{tabular}{cccc}
\hline Indikator & Skor & Range skor & Keterangan \\
\hline Visual activities & 1,473 & $1,470-1,750$ & Sangat aktif \\
Oral activities & 1,165 & $1,176-1,400$ & Sangat aktif \\
Listening activities & 1,306 & $1,470-1,750$ & Sangat aktif \\
$\begin{array}{c}\text { Mental activities dan } \\
\text { Emotional activities }\end{array}$ & 1,369 & $1,470-1,750$ & Sangat aktif \\
\hline Total & 5,313 & $5,586-6,650$ & Sangat aktif \\
\hline
\end{tabular}

Tabel 2 menunjukkan aktivitas belajar ekonomi siswa kelompok eksperimen yang diajar dengan model pembelajaran kooperatif tipe TPS dilihat dari indikator aktivitas belajar secara total skor 5,313 yang berada pada rentang skor 5,586 - 6,650. Hal ini menunjukkan siswa kelompok eksperimen yang diajar dengan model pembelajaran kooperatif tipe TPS dilihat dari indikator memiliki aktivitas belajar dalam kategori sangat aktif. 
Tabel 3. Aktivitas Belajar Ekonomi siswa Kelompok Kontrol

\begin{tabular}{ccccc}
\hline & Indikator & Skor & Range skor & Keterangan \\
\cline { 2 - 4 } Aktivitas belajar & $\begin{array}{c}\text { Visual } \\
\text { activities } \\
\text { Oral } \\
\text { activities } \\
\text { Listening } \\
\text { activities } \\
\text { Mental } \\
\text { activities dan } \\
\text { Emotional } \\
\text { activities }\end{array}$ & 1,077 & $931-1,175$ & Aktif \\
& 1,013 & $931-1,175$ & Aktif \\
Total & 1,063 & $931-1,175$ & Aktif \\
\hline
\end{tabular}

Tabel 3 menunjukkan aktivitas belajar ekonomi siswa kelompok kontrol yang diajar dengan model pembelajaran kooperatif tipe jigsaw terlihat dari indikator aktivitas belajar belajar secara total memiliki skor 4,119 yang berada pada rentang skor 3,807 - 4,703. Hal ini menunjukkan siswa kelompok kontrol yang diajar dengan model pembelajaran kooperatif tipe jigsaw dilihat dari indikator memiliki aktivitas belajar dalam kategori aktif.

Tabel 4. Hasil perhitungan group statistics

\begin{tabular}{lccccc}
\hline & Kelas & N & Mean & Std. Deviation & Std. Error Mean \\
\hline Aktivitas belajar Ekonomi & Kelas x ips 1 & 35 & 84.5143 & 4.04658 & .68400 \\
& Kelas x ips 2 & 35 & 76.7429 & 4.93691 & .83449 \\
\hline
\end{tabular}

Tabel 5 Hasil perhitungan Independent Samples Test

Levene's Test
for Equality of
Variances

\begin{tabular}{|c|c|c|c|c|c|c|c|c|c|c|}
\hline \multirow{4}{*}{$\begin{array}{l}\text { Aktivitas } \\
\text { belajar } \\
\text { Ekonomi }\end{array}$} & & \multirow[b]{2}{*}{$\mathrm{F}$} & \multirow[b]{2}{*}{ Sig. } & \multirow[b]{2}{*}{$\mathrm{t}$} & \multirow[b]{2}{*}{ Df } & \multirow{2}{*}{$\begin{array}{l}\text { Sig. (2- } \\
\text { tailed) }\end{array}$} & \multirow{2}{*}{$\begin{array}{c}\text { Mean } \\
\text { Difference }\end{array}$} & \multirow{2}{*}{$\begin{array}{l}\text { Std. Error } \\
\text { Difference }\end{array}$} & \multicolumn{2}{|c|}{$\begin{array}{l}\text { 95\% Confidence } \\
\text { Interval of the } \\
\text { Difference }\end{array}$} \\
\hline & & & & & & & & & Lower & Upper \\
\hline & $\begin{array}{c}\text { Equal } \\
\text { variances } \\
\text { assumed }\end{array}$ & 1.404 & .240 & 7.202 & 68 & .000 & 7.77143 & 1.07899 & 5.61833 & 9.92453 \\
\hline & $\begin{array}{c}\text { Equal } \\
\text { variances } \\
\text { not } \\
\text { assumed }\end{array}$ & & & 7.202 & 5.477 & .000 & 7.77143 & 1.07899 & 5.61683 & 9.92603 \\
\hline
\end{tabular}

Tabel 4 menunjukkan rata-rata aktivitas belajar pada kelompok eksperimen diperoleh mean 84,5143 dibulatkan menjadi 85 dan rata-rata aktivitas belajar pada kelompok kontrol diperoleh mean 76,7429 dibulatkan menjadi 77. Hal ini menunjukkan dari hasil rata-rata sementara dapat ditarik kesimpulan ada perbedaan aktivitas belajar siswa pada kelompok eksperimen dan kelompok kontrol. Selanjutnya untuk menguji signifikansi perbedaan maka digunakan analisis uji hipotesis. Berdasarkan hasil analisis yang di dapat nampak pada tabel 5 . 
Berdasarkan tabel 5 diketahui hasil $\mathrm{t}$ diperoleh $\mathrm{t}_{\text {hitung }}$ sebesar 7,202 sedangkan $\mathrm{t}_{\text {tabel }}$ denngan taraf signifikasi 5\% diperoleh 1,66757. Dengan demikian, diketahui bahwa nilai thitung $>t_{\text {tabel }}(7,202>1,66757)$, maka Ha diterima dan Ho ditolak. Artinya terdapat perbedaan yang signifikan antara aktivitas belajar ekonomi siswa kelompok eksperimen dan kelompok kontrol.

\section{Pembahasan}

Berdasarkan hasil penelitian yang telah dilakukan diketahui terdapat perbedaan yang signifikan antara aktivitas belajar siswa kelompok eksperimen dan kelompok kontrol. Hasil penelitian ini menunjukkan skor nilai rata-rata aktivitas belajar pada kelompok eksperimen lebih aktif dibandingkan dengan skor nilai rata-rata aktivitas belajar pada kelompok kontrol. Walaupun demikian, keduanya dapat dikategorikan samasama aktif. Perbedaan aktivitas belajar dilatarbelakangi oleh faktor internal dan eksternal yang dilihat dari indikator aktivitas belajar antara lain, visual activities, oral activities, listening activities, mental activities dan emotional activities. Dalam proses pembelajaran yang diamati kesehariannya, siswa pada kelompok eksperimen dibandingan dengan siswa kelompok kontrol memang terlihat siswa pada kelompok eksperimen yang memiliki aktivitas belajar lebih tinggi. Jika diamati secara langsung aktivitas belajar pada kelompok eksperimen aktif bertanya apabila ada suatu hal yang belum dipahami, selain itu siswa aktif dan sangat antusias dalam mengemukakan pendapat maupun menjawab pertanyaan yang diberikan.

Berbeda halnya dengan aktivitas belajar pada kelompok kontrol yang terlihat hanya beberapa siswa yang aktif, selain itu apabila ada materi yang belum mereka pahami hanya berdiam dan hanya beberapa siswa yang berani mengemukakan pendapat dan pertanyaan yang diberikan. Penelitian ini didukung dengan teori yang dipaparkan oleh Sardiman (2011) yang menyatakan bahwa aktivitas belajar ialah prinsip asas yang diperlukan dalam interaksi belajar mengajar, secara umum indikator aktivitas belajar meliputi visual activities, oral activities, listening activities, mental activities, emotional activities. Penelitian ini juga sejalan dengan penelitian yang dilakukan oleh Ipan Nugraha (2017) yang menyatakan terdapat perbedaan aktivitas belajar siswa dengan menggunakan model pembelajaran kooperatif tipe TPS dan tipe Jigsaw.

\section{Implikasi}

Implikasi dalam penelitian ini ialah adanya perubahan perolehan skor aktivitas belajar siswa menjadi sangat aktif. Keaktifan siswa dalam kegiatan pembelajaran berdampak pada perolehan KKM. KKM untuk mata pelajaran ekonomi yaitu 70 yang berada pada kategori cukup dan sudah melampaui dari KKM (Kriteria Minimal Ketuntasan). Ekonomi merupakan mata pelajaran yang wajib diberikan, karena ekonomi merupakan matapelajaran yang sangat penting dalam Jurusan IPS. Hasil aktivitas belajar pada kelompok eksperimen dan kelompok kontrol dikategorikan sama-sama aktif namun perlu ditingkatkan lagi, dikarenakan masih ada beberapa siswa yang masih ada pada kategori cukup.

\section{Simpulan dan Saran}

\section{Simpulan}

Berdasarkan hasil analisis data dan pembahasan hasil penelitian maka dapat ditarik kesimpulannya. Adapun simpulannya ialah pertama, aktivitas belajar siswa pada kelompok eksperimen dengan menggunakan model pembelajaran kooperatif tipe TPS ada pada kategori sangat aktif. Kedua, aktivitas belajar siswa pada kelompok kontrol dengan menggunakan model pembelajaran kooperatif tipe jigsaw ada pada kategori aktif. Ketiga, terdapat perbedaan yang signifikan antara aktivitas belajar siswa yang diajar dengan menggunakan model pembelajaran kooperatif tipe TPS pada kelompok eksperimen dengan model pembelajaran kooperatif tipe jigsaw pada kelompok kontrol.

\section{Saran}

Berdasarkan simpulan tersebut, maka dapat dikemukakan saran sebagai berikut. Saran yang disampaikan ialah pertama, bagi guru, disarankan bagi guru dalam melaksanakan proses pembelajaran penting hal nya untuk kita menerapkan model pembelajaran apapun untuk meningkatkan aktivitas belajar siswa agar segala tujuan pembelajaran mencapai tujuan yang diinginkan. Kedua, bagi peneliti lain, diharapkan akan dapat memanfaatkan hasil penelitian ini sebagai salah satu referensi pembelajaran serta dapat mengembangkan hasil penelitian dimasa yang akan datang.

\section{Daftar Rujukan}


Apriliawati. (2011). Penerapan Strategi Motivasi ARCH Dalam Pembelajaran Kooperatif tipe STAD. Jurnal Pendidikan.

Ayuwanti, I. (2017). Meningkatkan Aktivitas dan Hasil Belajar Matematika Menggunakan Model Pembelajaran Kooperatif Tipe Group Investigation di SMK Tuma'ninah Yasin Metro. SAP (Susunan Artikel Pendidikan), 1(2), 105-114. https://doi.org/10.30998/sap.v1i2.1017

Canessia D.Putri, N. M., Ardana, I. K., \& Agustika, G. N. S. (2019). Pengaruh Model Discovery Learning Berbantuan Lingkungan Terhadap Kompetensi Pengetahuan IPA Siswa Kelas V. Mimbar PGSD, 7(2), 5764.

Catur Saputro, A. N., Istiana, G., \& Sukardjo, J. (2015). Penerapan Model Pembelajaran Discovery Learning Untuk Meningkatkan Aktivitas Dan Prestasi Belajar Pokok Bahasan Larutan Penyangga Pada Siswa Kelas Xi Ipa Semester Ii Sma Negeri 1 Ngemplak Tahun Pelajaran 2013/2014. Jurnal Pendidikan Kimia Universitas Sebelas Maret, 4(2), 65-73.

Darmadi, H. (2014). Metode Penelitian Pendidikan Sosial. Alfabet.

Dr. Rusman. (2012). model-model pembelajaran mengembangkan profesionalisme guru. PT Raja Grafindo Persada.

Ibrahim, dkk. (2011). Pembelajaran Kooperatif. Unesa Press.

Isjoni. (2013). Pembelajaran Kooperatif: Meningkatkan Kecerdasan Komunikasi antar Peserta Didik. Pusaka Pelajar.

Januartini, P. D., Agustini, K., \& Sindu, I. G. P. (2016). Studi Komparatif Model Pembelajaran Think Pair Square Dan Think Pair Share Terhadap Motivasi Dan Hasil Belajar Siswa Mapel Tik Kelas X Sma N 1 Sukasada. Jurnal Pendidikan Teknologi Dan Kejuruan, 13(2), 148-160. https://doi.org/10.23887/jptk.v13i2.8523

Karyawati, N. K., Murda, I. N., \& W., \& W, I. (2014). Pengaruh Model Pembelajaran Kooperatif Tipe Think Pair Square ( TPS ) Berbantuan Kartu Kerja terhadap Hasil Belajar Matematika. Jurnal Mimbar PGSD Universitas Pendidikan Ganesha.

Kusuma, F. W., \& Aisyah, M. N. (2012). Implementasi Model Pembelajaran Kooperatif Tipe Think Pair Share Untuk Meningkatkan Aktivitas Belajar Akuntansi Siswa Kelas Xi Ips 1 Sma Negeri 2 Wonosari Tahun Ajaran 2011/2012. Jurnal Pendidikan Akuntansi Indonesia, 10(2), 43-63. https://doi.org/10.21831/jpai.v10i2.912

Oemar Hamalik. (2010). proses belajar mengajar. PT Bumi Aksara.

Permendikbud. (2014). Pembelajaran Pada Pendidikan Dasar dan Pendidikan Menengah. Peraturan Menteri Pendidikan Dan Kebudayaan Republik Indonesia Nomor 103 Tahun 2014.

Redno setiawan. (2018). peningkatan hasil belajar ekonomi dengan menggunakan model pembelajaran kooperatif tipe jigsaw kelas XI IIS SMA Negeri 2 Palangkaraya. Jurnal Pendidikan Ekonomi.

Sardiman. (2011). Interaksi \& Motivasi Belajar Mengajar. PT Raja Grafindo Persada.

Sari, L. W., Cawang, C., \& Kurniawan, R. A. (2017). Aktivitas Belajar Siswa Pada Materi Stuktur Atom Kelas X Mia Sekolah Menengah Atas Negeri 4 Pontianak. AR-RAZI Jurnal Ilmiah, 5(1). https://doi.org/10.29406/arz.v5i1.652

Slameto. (2010). Belajar dan faktor-faktor yang Mempengaruhinya. PT. Rineka Cipta.

Suprijono, A. (2013). Cooperative Learning Teori dan Aplikasi PAIKEM. Pustaka Belajar.

Suriati, S. (2019). Analisis Prestasi Belajar Matematika : Dampak Model Pembelajaran Kooperatif Tipe ThinkPair-Square Ditinjau dari Aktivitas Belajar. Desimal: Jurnal Matematika, 2(2), 181-188. https://doi.org/10.24042/djm.v2i2.4374 